\title{
Introducción al dossier: Literaturas, memorias, testimonios
}

\author{
Samanta Rodríguez \\ samantaro@gmail.com \\ Universidad Nacional de La Plata, Argentina \\ Emiliano Tavernini \\ emilianotavernini@gmail.com \\ Universidad Nacional de La Plata, Argentina
}

Cita sugerida: Rodríguez, S. y Tavernini, E. (2020). Introducción

al dossier: Literaturas, memorias, testimonios. Aletheia, 11(21),

e063. https://doi.org/10.24215/18533701e063

El presente dossier vuelve a la pregunta por los vínculos entre la literatura contemporánea y las configuraciones emergentes de la memoria social, histórica y política sobre el pasado reciente latinoamericano. Nos proponemos explorar diversos modos en que la literatura y la escritura -literaria y académica- releen tradiciones para dar lugar a los trabajos y rituales de la memoria, y también para reivindicar su agencia en la transformación de los estatutos del testimonio. ¿Cómo pensar hoy la literatura y el arte en tanto territorios de memorias ${ }^{1}$ no fosilizadas? ¿Cuáles son los corpus narrativos y poéticos que emergen mediante lecturas que incorporan la perspectiva de género o el paradigma de las teorías de los afectos? ¿Cuáles son lxs cuerpxs invisibilizadxs y violentadxs por la racionalidad del estado patriarcal y las lenguas que vienen a desarmarlo? ¿Qué le dicen hoy la literatura y las nuevas formas del testimonio a ese orden cultural? ¿Qué valor cobra lo poético en la revelación de los mecanismos del recuerdo y de la memoria? ¿De qué modo la ficción evoca experiencias del orden de lo vivido, o toca lo real, y cuáles son los límites de los intentos miméticos, testimoniales y comunicativos?

Estas preguntas hacen eco en los debates actuales del campo de las ciencias sociales y de la historia en torno a los modos de abordar el pasado reciente, de los que darán cuenta los trabajos incluidos en este dossier ${ }^{2}$. La literatura, a la par que estas disciplinas "interviene en la elaboración del pasado de manera fecunda [porque] no se apresura a concluir o a clausurar, por el contrario, complejiza nuestra aprehensión de la historia, permite pensar sus singularidades y su multiplicidad, explora los vínculos -muchas veces incómodos- entre pasado 
y presente" (Delgado et al. 2004, s/p). En las estrategias de significación se despliegan nudos claves de la comprensión histórica, el valor y las formas legítimas del testimonio, las transmisiones y filiaciones que enhebran los (des)acuerdos entre generaciones, los modos que una sociedad se da para rememorar su pasado (Escobar et al., 2015).

Por otra parte, consideramos relevante en el marco de Aletheia contribuir con una perspectiva interdisciplinar que contemple el abordaje de la literatura no solamente como objeto cultural que da testimonio de unos acontecimientos históricos, sociales, políticos y que haría sentido únicamente por su carácter referencial o ejemplificador; sino un abordaje donde la literatura se entienda como participante activa en la construcción y sostenimiento de políticas de la memoria, acortando la distancia del yo al nosotrxs en una encrucijada compleja donde la memoria, los imaginarios de lo nacional, las representaciones de la historia y las identidades de sus actores están permanentemente en juego y en disputa. Esto significa entender a la literatura como atravesada por tensiones de poder, enlazada a la experiencia colectiva ahí donde la recuperación de experiencias y las elaboraciones estéticas de la memoria del pasado evidencian posiciones éticas, y en muchos casos explícitamente inscripciones políticas, en unas temporalidades presentes, marcadas por presencias y ausencias extra-textuales: de actores, de políticas de reparación, de trabajos de memoria.

La literatura se convertiría así en un "territorio de memorias" tal como lo entiende Ludmila Da Silva Catela (2002) quien retoma la noción de "lugares de memoria" de Pierre Nora pero prefiere alejarse de las connotaciones que implica el sustantivo "lugar", asociadas a un fenómeno estático, completo y determinado ${ }^{3}$. Por el contrario, la idea de territorio permite reconocer un espacio de disputas donde se produce la circulación emocional y afectiva de signos -susceptibles de ser conquistados, defendidos, redelimitados- que refuerzan el carácter social de aquellos conflictos que en distintos contextos represivos o violentos se percibían como íntimos o privados. Estas prácticas propenden a la construcción de un archivo que en el siglo XXI posibilita nuevos vínculos sociales, jerarquiza conocimientos y contribuye a la reconstrucción de un tejido colectivo solidario antes destruido por los genocidios y ahora acechados por nuevas formas de la violencia relacionadas con la trata de personas, el narcotráfico, los desplazamientos forzados, entre otras.

En ese sentido, cada trabajo del dossier -que en este número desborda hacia las secciones de Traducciones $y$ Entrevistas - constituye un espacio desde el cual mapear itinerarios significativos de lecturas que atraviesan temporalidades y territorios: desde una torsión de la lengua poética y mestiza que fusiona la cultura mapuche, la alemana y la criolla del Pucón chileno (en la poesía de Gloria Dünkler) hasta el diálogo transgeneracional en la traducción rioplatense de la lengua de una hija del exilio (Alicia Partnoy traduce la poesía de Ruth Irupé Sanabria). Desde una relectura de lxs cuerpxs en tanto espacios de intensidades que saturan las formas y localizan no sólo las condiciones de posibilidad de prácticas violentas sino los caminos de emancipación y reparación hacia un territorio donde ellas no son ni serán asesinadas (en lo artículos de Silvana Mandolessi y de Miriam Chiani respectivamente), pasando por la poesía de cordel guerrillero que retorna del mato de Araguaia para señalar la resistencia de la voz poética en el archivo sobreviviente de un exterminio negado (en el trabajo de Ivania Melo y Tânia Sarmento-Pantoja). Nuestro itinerario atraviesa las zonas híbridas a las que abreva el género testimonial en los contextos del presente, esto es, "ni absoluto literario ni pureza testimonial" (tal como sostiene en su estudio Teresa Basile) sino más bien un saber decir la violencia que entrañan las historias locales latinoamericanas desde espacios de enunciación babélicos. ¿Dónde nos ubican las palabras que decimos?, una de las preguntas del trabajo de Perla Sneh nos permite, por fin, mapear los territorios donde se imbrican temporalidades históricas, lenguas y memorias como experiencias de resistencia y combate transmisibles, cuya apropiación en otras tramas culturales permite mantener un "alerta universal” frente a crímenes singulares. Una arista de aquello que Pádua Fernandes reivindica en su trabajo de "desarchivamiento del Brasil" cuando trae una zona de la poesía escrita en portugués brasileño que tiene por tarea la creación de un suelo (una lengua, una historia) común que deconstruya a su vez, el olvido.

El artículo de Ivania Melo y Tânia Sarmento-Pantoja titulado: "A poética da resistência nos poemas sobre a Guerrilha do Araguaia: o corpus do jornal Resistência” trabaja sobre poemas que tienen como tema 
la Guerrilla del Araguaia y forman parte de un conjunto de textos publicados en el periódico brasileño Resistência en febrero de 1979. El artículo reconstruye aspectos históricos y experiencias singulares alrededor del proyecto revolucionario que iniciaría en la región llamada Bico do Papagaio, zona de frontera entre los estados brasileños de Maranhão, Pará y Tocantins. El plan de exterminio de los grupos guerrilleros -que se desplazaron sobre todo desde São Paulo y habían comenzado a instalarse en 1966 en la cuenca del río Araguaia- movilizó millares de militares a la región en el transcurso de dos años (1972-1974) que pusieron en práctica la tecnología de poder desaparecedora. Las lecturas de Melo y Sarmento-Pantoja atraviesan un archivo del periodismo cultural que accionaba contra las políticas dictatoriales desde Belén do Pará, de allí recortan un archivo poético sobre Araguaia para rejerarquizarlo en el paradigma de las "poéticas de la resistencia”. Ese movimiento implica también una actualización y un dar a ver -una reaparición deargumentos, datos, antecedentes, actorxs, lenguajes e imaginarios que envuelven un episodio todavía poco profundizado en la historia reciente latinoamericana. Con marcas de polifonía, en la tradición de la literatura de cordel, producidos para la circulación entre campesinos de la región, estos poemas expresan demandas colectivas por derechos y libertades negados todavía hoy a la ciudadanía brasileña. Los actuales movimientos por el derecho a la tierra, las manifestaciones contra el ecocidio y el genocidio indígena también reverberan en aquella lengua que el estado buscó exterminar.

Por su parte, "Poesia brasileira e ditadura: memória e desaparecimento em Ricardo Domeneck, Eduardo Sterzi, Paulo Ferraz e Priscila Figueiredo" de Pádua Fernandes presenta una cartografía de poetas que, desde distintas estéticas y posicionamientos políticos, forman parte del "nuevo ciclo de memoria cultural" que conoce Brasil en el siglo XXI, y vuelca su análisis hacia un corpus de poesía escrita en tiempos de justicia de transición. Género dejado de lado frecuentemente en los estudios críticos sobre el tema, la poesía, argumenta el autor, contribuye a la creación de una memoria crítica que, con sus imágenes y discursos, abona el proceso de creación social de la justicia de transición. Para ello, además de un enfoque dialógico entre las producciones brasileñas con la poesía escrita por los HIJOS argentinos, este artículo actualiza e interpreta, en el análisis del corpus poético, una serie de eventos históricos y políticos, de represión a la cultura y de resistencia cultural, que tuvieron lugar en Brasil desde la década del 60 hasta el presente y que permiten repensar la literatura como un activo documento de la historia en tiempos de recrudecimiento de los discursos del odio y del negacionismo.

"Formas de (des)afección: Dos veces junio de Martín Kohan" de Silvana Mandolessi nos introduce en el caso argentino mediante el análisis de la novela de Kohan desde la teoría de los afectos, y abre la posibilidad de una clave de lectura inédita para otras novelas sobre el genocidio publicadas en la posdictadura. La noción de afecto, sostiene Mandolessi, permite comprender el microfuncionamiento del poder autoritario: se materializa localmente allí donde satura las formas por lo que contribuye a la inscripción del pasado superviviendo en el presente y posee el potencial de revelar "el sentido más oculto -y más original- de la memoria”. Centrado en el protagonista de la novela, agente de la tortura y la desaparición, el análisis crítico hace foco en su marcada desafección y ensaya una explicación del comportamiento de la sociedad civil en el marco de la realización del genocidio: "un momento o una esfera histórica determinada regula e intensifica ciertas respuestas efectivas -y atenúa otras". A su vez, este trabajo realiza un aporte a los debates en torno a las limitaciones del concepto de trauma en los estudios sobre memoria dado que, como plantea la autora, imperó en muchos casos una experiencia de "no excepcionalidad" por lo que propone explorar la dialéctica de indiferencia, silencio y complicidad de quienes no pueden ser clasificados dentro de la dicotomía víctimas/ perpetradores.

En "Reinstitucionalización del testimonio en América Latina desde la narrativa humanitaria" Teresa Basile propone un minucioso abordaje de la literatura testimonial latinoamericana desde dos matrices contextuales que asignan diversos sentidos al género: una matriz revolucionaria institucionalizada en 1970 por Casa de las Américas -en un momento en que vanguardia política y artística todavía no habían entrado abiertamente en colisión dentro del proceso revolucionario cubano- y una matriz humanitaria que emergió 
en la década del ochenta en las sociedades posdictatoriales, cuya institucionalización estuvo determinada por los discursos y el activismo de los organismos de Derechos Humanos. Basile realiza un balance de cada una de las tipologías que convivieron dentro de cada matriz con el fin de destacar un tercer momento -en proceso de desarrollo- en el que asistimos "a un movimiento centrífugo por el cual el testimonio se instaura como plataforma para luego fugar de su pacto de verdad-realidad y contaminarse con (o alimentarse de) la perturbadora ficción". La pregunta por el surgimiento de una era del testigo en las posdictaduras del Cono Sur motoriza un análisis sobre el desarrollo de este nuevo estatuto del testimonio de matriz humanitaria así como de su "plasticidad" para adaptarse a coyunturas diversas, trabajarse en lenguajes y "usos" disímiles, abrir la posibilidad a preguntas no tan cómodas -¿puede considerarse un represor testigo?- o mostrar su actualidad y potencia allí donde es tomado por víctimas vinculadas a otras formas de violencia (femicidios, gatillo fácil, narcoviolencia, migrantes, racismo, etc.).

Miriam Chiani en "Violencia, memoria y género. Gabriela Cabezón Cámara, Marta Dillon, Selva Almada, Mariana De Mello, Belén López Peiró” articula los estudios sobre memoria del pasado reciente con los estudios de género para presentarnos y leer un corpus de novelas de una segunda generación de escritoras argentinas: narrativas de hijas de desaparecidos y exiliados, y textos sobre violencia de género que establecen en diferentes grados diversas relaciones con la violencia política -sexuada- de los años '70. En palabras de la autora, "escrituras que piensan las violencias del patriarcado como terrorismo de Estado; escrituras de la violencia política que develan su faz patriarcal". En ellas, la imagen del pasado y la racionalidad patriarcal emerge de los conflictos del presente, retorna en las narraciones junto a lxs cuerpxs aparecidxs o sobrevivientes. Walter Benjamin denominaba Jetztzeit - "tiempo del ahora"- al momento específico en que el pasado colisiona con el presente y resurge en él: a la manera benjaminiana, Chiani plantea que recordar implica cambiar el presente y en este sentido sólo la transformación política acarrearía una posible redención de aquello que ha sucedido y ha sido derrotado. En este sentido, no es la inmediatez que acucia a estas nuevas voces emergentes a mediados de los 2000 en un contexto de masificación y reorganización de los movimientos de mujeres y LGTBI, sino la necesidad de, parafraseando a Almada, reconstruir cómo las miraron y las miran a ellas, a través de proyectos de escritura que torsionan los estatutos del testimonio.

Perla Sneh en "Shoah y palabras: la memoria como combate" nos introduce en los procesos de rememoración transcultural y multidireccional que habilita la literatura. La inspiración que encontró la resistencia del gueto de Varsovia en la novela Los cuarenta dias de Musa Dagh (1933) de Franz Werfel escrita en alemán por un autor judío y que narra las peripecias de un personaje armenio en el contexto del Genocidio turco- lleva a Sneh a preguntarse cómo fue leído este texto que permitía "registrar aquello que la información no alcanzaba a transmitir" y desplegar la memoria como combate -esto es, acciones de resitencia, retornos al mundo de la acción- al interior de experiencias límite donde las palabras navegan entre amenzas de aniquilamiento. El análisis de Sneh abona, mediante el estudio de un caso específico, a la teoría de Michael Rothberg respecto de que la memoria pública es estructuralmente multidireccional, es decir, marcada siempre "por el préstamo, el intercambio y la adaptación transcultural" (Rothberg, 2015, p. 23); una de las formas posibles de promover un estado de alerta universal donde cobran relevancia las modulaciones de las lenguas que "cargan sus propias cifras de sangre" -un vocablo judío, un término armenio, unos modos de decir en español rioplatense que señalan, aún, geografías del terror.

Para la sección "Entrevistas" conversamos con la poeta chilena Gloria Dünkler porque en su obra el trabajo con el testimonio, la historia oral y los archivos documentales es estructurante. Indagamos en el proceso de escritura de sus cuatro poemarios con la convicción de que sus poemas documentales aportan a la comprensión de un fenómeno trasnacional, característico del siglo XXI, que se propone intervenir desde la escritura poética distintos archivos históricos.

En la sección "Conferencias y traducciones" incluimos una presentación, selección y traducción de la obra poética de Ruth Irupé Sanabria realizada por su madre, la escritora Alicia Partnoy ${ }^{4}$. Ruth Sanabria es una exiliada hija ${ }^{5}$ radicada en Estados Unidos. La dictadura había obligado a sus padres, sobrevivientes del Centro 
Clandestino de Detención "La escuelita" de Bahía Blanca a exiliarse en ese país, motivo por el cual "para esta familia la condena por sus ideas políticas no termina con el exilio, como generalmente se suponía” (Ros, 2016, p. 244). En el país de destino la comunidad de refugiados fue muy reducida -a diferencia de otros países que recibieron exiliados argentinos como España, México, Suecia o Francia- y la familia fue etiquetada rápidamente de una manera semejante a como la clasificaba el régimen militar argentino. En la poética de Sanabria el sujeto social asume una voz que se identifica con el colectivo de los exiliados hijos, pero también con el de los migrantes latinoamericanos en Estados Unidos. De la misma manera el yo lírico va a constituirse apropiándose de la lengua de la madre, de la obra de la abuela -la pintora Raquel Partnoy-, de la sociedad de residencia, así como de la lengua de los represores que declararon en el juicio al V Cuerpo del Ejército de Bahía Blanca. En un artículo reciente Laura Loustau (2019) plantea que la mayoría de los trabajos sobre las producciones artísticas de hijos e hijas de perseguidos políticos en los setenta por lo general no tienen en cuenta la gran cantidad de material que circula por fuera de la Argentina, dado que muchos exiliados hijos se han radicado definitivamente en el extranjero. Por este motivo es que nos propusimos difundir parte de una obra en la que los diálogos transgeneracionales adquieren una gran relevancia porque dan cuenta de la dinámica y la vitalidad de los procesos de memoria que habilita la poesía haciendo público lo íntimo familiar.

Finalmente, esperamos que lxs lectorxs disfruten al igual que nosotrxs de estos artículos y que los mismos contribuyan no sólo a aportar material de estudio para lxs especialistas del campo de la literatura sino también que permitan pensar nuevos problemas y desafíos a otras disciplinas como la historia, la sociología, la historia del arte o las ciencias de la educación.

\section{REFERENCIAS}

Alberione, E. (2016). Narrativas contemporáneas de los exiliados hijos: Esa particular manera de contar-se, IX Seminario Politicas de la memoria, Centro Cultural de la Memoria Haroldo Conti.

Da Silva Catela, L. (2002). Territorios de memoria política. Los archivos de la represión en Brasil. En L. Da Silva Catela y E. Jelin (comp.), Los archivos de la represión: documentos, memoria y verdad (pp.15-84). Buenos Aires/Madrid: Siglo XXI Editores.

Delgado, V.; Merbilhaá, M.; Príncipi, A. y Roger, G. (2004). Literatura y memoria, Puentes “Dossier Educación y memoria",13. Recuperado de: https://www.comisionporlamemoria.org/archivos/jovenesymemoria/bibliografi a_web/ejes/cultura_delgado2.pdf

Escobar, L.; Giordano, J. y Pittaluga, R. (2015). Presentación. En Escobar, L.; Giordano, J. y Pittaluga, R. (comp.). Figuraciones estéticas de la experiencia argentina reciente (pp. 9-16). Santa Fe: María Muratore.

Loustau, L. (2019). Poesía, arte y diálogos transgeneracionales en Beasts Behave in Foreign Lands de Ruth Irupé Sanabria. Taller de Letras, (65), 141-148.

Ros, A. (2016). Ruth Irupé Sanabria: la poesía militante como forma de habitar el desarraigo. En Feierstein, Liliana y Zylberman, Lior (ed.), Narrativas del terror y la desaparición en América Latina (pp. 239-252). Buenos Aires: Eduntref.

Rothberg, M. (2015). De Gaza a Varsovia: hacia un mapa de la memoria multidireccional. En S. Mandolessi y M. Alonso (eds.), Estudios sobre memoria. Perspectivas actuales y nuevos escenarios (pp. 21-51). Villa María: Eduvim.

Sazbón, J. (2002). Conciencia histórica y memoria. Prismas. Revista de historia intelectual, 6 (1), pp. 21-43.

\section{Notas}

1 Ludmila Da Silva (2002) retoma la noción de "lugares de memoria" de Pierre Nora pero prefiere alejarse de las connotaciones que implica el sustantivo "lugar", que da la idea de un fenómeno estático, completo y determinado. Por el contrario la idea de territorio permite demarcar un espacio de disputas, susceptible de ser conquistado, defendido, redelimitado, etc. Un espacio sui generis, siempre nuevo luego de cada disputa, en la que se producen continuas negociaciones en las interpretaciones que los abordan. 
2 Como señala Raphael Samuel la historia es "una forma orgánica de conocimiento, forma cuyas fuentes son promiscuas, basadas no sólo en la experiencia de la vida real sino también en la memoria y en el mito, en la fantasía y en el deseo; no sólo en el pasado cronológico del registro documental sino también el intemporal de la tradición” (Sazbón, 2002, p. 21).

3 Da Silva coincide con Nora cuando dice que la memoria "es más un marco que un contenido, un desafío siempre disponible, un conjunto de estrategias, un estar-ahí que vale menos por lo que es que por lo que se hace con ella” (Da Silva, 2002, p. 22).

4 Ha publicado The little school: tales or dissapearance and survival in Argentina (1986), Venganza de la manzana (1992), Volando bajito (2005) y Flowering Fires/Fuegos Florales (2015).

5 Eva Alberione propone definir de esta manera la experiencia en el exilio de hijos e hijas en "Narrativas contemporáneas de los exiliados hijos: Esa particular manera de contar-se” (2016). Los beneficios del concepto radicarían según Alberione en que "de algún modo pone foco en la percepción o incluso en la propia conciencia de los hijos acerca del accionar del terrorismo de estado sobre sus propios cuerpos y sus vidas, y no sólo sobre las de sus padres" (5). Como antecedentes de la propuesta de la autora se encuentra el film de Violeta Burkart Noé y Analía Miller Argenmex, exiliados hijos (2007), mientras que María Rosa Lojo la enuncia en un artículo de 2010 "Los hijos del amor y del espanto" con motivo de la conmemoración de los 70 años del exilio Republicano español. 